\title{
On the electro-oxidation of small organic molecules: towards a fuel cell catalyst testing platform with realistic reaction environment
}

Damin Zhang ${ }^{\mathrm{a}}$, Jia Du ${ }^{\mathrm{a}}$, Jonathan Quinson ${ }^{\mathrm{b}}$, Matthias Arenz ${ }^{\mathrm{a}}$

a Department of Chemistry, Biochemistry and Pharmaceutical Sciences, University of Bern, Freiestrasse 3, 3012 Bern, Switzerland

b Department of Chemistry, University of Copenhagen, Universitetsparken 5, 2100 Copenhagen $\emptyset$, Denmark

* Corresponding author: matthias.arenz@unibe.ch

\begin{abstract}
The electrocatalytic oxidation of small organic compounds such as methanol or formic acid has been the subject of numerous investigations in the last decades. The motivation for these studies is often their use as fuel in so-called direct methanol or direct formic acid fuel cells, promising alternatives to hydrogen-fueled proton exchange membrane fuel cells. The fundamental research spans from screening studies to identify the best performing catalyst materials to detailed mechanistic investigations of the reaction pathway. These investigations are commonly performed in standard three electrode electrochemical cells with a liquid supporting electrolyte to which the methanol or formic acid is added. In fuel cell devices, however, no liquid electrolyte will be present, instead membrane electrolytes are used. The question therefore arises, to which extend results from conventional electrochemical cells can be extrapolated to conditions found in fuel cells. We previously developed a gas diffusion electrode setup to mimic "real-life" reaction conditions and study electrocatalysts for oxygen gas reduction or water splitting. It is here demonstrated that the setup is also suitable to investigate the properties of catalysts for the electro-oxidation of small organic molecules.
\end{abstract}


Using the gas diffusion electrode setup, it is seen that employing a catalyst - membrane electrolyte interface as compared to conventional electrochemical cells can lead to significantly different catalyst performances. Therefore, it is recommended to implement gas diffusion electrode setups for the investigation of the electro-oxidation of small organic molecules.

\section{Keywords}

Methanol oxidation; formic acid oxidation; direct methanol fuel cell; direct formic acid fuel cell; gas diffusion electrode setup;

\section{Introduction}

Energy conversion and storage are the most prominent applications of electrochemistry. Electrochemical energy conversion is required to use electric energy for producing fuels and chemicals, e.g., in water electrolysis or carbon dioxide electroreduction, but also to transform fuels to electric energy. The most common fuel thereby is gaseous hydrogen, which can be converted into electric energy using proton exchange fuel cells (PEMFCs). Hydrogen powered PEMFCs are for example used in automotive applications where an extremely high-power density is required [1]. The main challenges for the technology however are the lack of a hydrogen distribution system and the high costs [2]. Liquid fuels by comparison are easier to distribute and store. However, operating PEMFCs with liquid fuels in so-called direct liquid fuel cells requires substantially larger amounts of the precious and rare catalyst materials to reach a given $\mathrm{kW}$ peak power demand due to the sluggish anode reaction [3] in addition to the limited cathode performance. Nevertheless, direct liquid fuel cells are an interesting alternative for applications where lower power densities are required. Examples for direct liquid fuel cells are direct methanol and direct formic acid fuel cells (DMFC and DFAFCs) [4].

The first steps in catalyst development for PEMFCs are usually performed in rotating disk electrode (RDE) measurements in three-compartment electrochemical cells with liquid 
electrolyte.[5] Such experiments are straightforward to set up, but for cathode catalysts promoting the oxygen reduction reaction (ORR), it has been observed that the extrapolation of the results to real applications or even measurements in single cell membrane electrode assemblies (MEA) is challenging [6]. This is mostly due to different mass transport conditions, but the electrolyte environment in PEMFCs is also considerably different than in RDE measurements. For this reason, several research groups developed experimental approaches for catalyst testing that aim to establish a second testing platform bridging RDE and MEAs; [7,8,17-19,9-16] one of these platforms is the gas diffusion electrode (GDE) setup. As pointed out, the main motivation in developing GDE setups is to establish high reactant mass transport which is crucial for gaseous reactants such as oxygen [13]. However, also the electrolyte type, i.e., liquid or membrane, is expected to have a significant influence on the catalyst reactivity. It is well known for example that the determined ORR activity of Pt based catalysts is substantially different in sulfuric and in perchloric acid based aqueous electrolytes [20]. This phenomenon is related to structure sensitive, specific anion adsorption blocking active catalyst sites and the term spectator species was introduced for anions in the liquid electrolyte as they have no active part in the ORR. Nafion, by comparison, which is often used as membrane electrolyte, does not exhibit structure specific adsorption, although it blocks active catalyst sites as well $[21,22]$.

Although it has been shown that even non-specifically absorbed cations can influence catalytic reactions [23], to the best of our knowledge so far it has not been investigated to which degree the electrolyte environment, i.e., aqueous or membrane electrolyte, influences the oxidation of small organic molecules, e.g., methanol and formic acid. In the present study, we therefore compare the performance of two standard catalysts for the methanol and formic acid oxidation, i.e., Pt and $\mathrm{Pd}$ nanoparticles supported on high surface area carbon $(\mathrm{Pt} / \mathrm{C}$ and $\mathrm{Pt} / \mathrm{C})$ and performed investigations in a conventional electrochemical setup as well as in a GDE setup. It 
is demonstrated that the two different environments, membrane electrolyte and liquid electrolyte, can indeed lead to different electrochemical behavior / performances. The study therefore suggests that implementing the GDE approach for the testing of direct methanol/formic acid oxidation catalysts is an important step towards more realistic reaction conditions.

\section{Experimental Methods}

\section{Materials and chemicals}

The following materials and chemicals were used: Commercial Pt/C (Tanaka Kikinzoku Group, TEC10E20A, 19.4\%) and Pd/C (FC Catalyst, 3151611, 20\% Palladium on Vulcan), $37 \%$ hydrochloric acid ( $\mathrm{HCl}$, Suprapur, Merck), 65\% nitric acid $\left(\mathrm{HNO}_{3}\right.$, Suprapur, Merck), methanol $\left(\mathrm{CH}_{3} \mathrm{OH}\right.$, VWR Chemicals, 98.5\%), formic acid (HCOOH, $\geq 95 \%$, Sigma Aldrich), isopropanol (IPA, 99.7+\%, Alfa Aesar), 70\% perchloric acid $\left(\mathrm{HClO}_{4}\right.$, ACS reagent, $70 \%$, Sigma-Aldrich), KOH (pellets for analysis EMSURE®,Merck), Nafion ${ }^{\mathrm{TM}}$ D1021 Dispersion (Water based $1100 \mathrm{EW}$ at $10 \mathrm{wt} \%$ ), Ultrapure water (resistivity>18.2 $\mathrm{M} \Omega \cdot \mathrm{cm}$, total organic carbon (TOC) < $5 \mathrm{ppb}$ ) from a Milli-Q system (Millipore). The following gases from Carbagas AG were used for electrochemical measurements: Ar (99.999\%), and CO (99.97\%). Gas

Diffusion Layer (GDL) without a Microporous Layer (MPL) (Freudenberg H23), Gas Diffusion Layer (GDL) with a Microporous Layer (MPL) (Freudenberg H23C8) and Nafion membrane (Nafion 117, Fuel Cell Store) or anion exchange membrane (Sustainion ${ }^{\circledR}$ X37-50 Grade RT, Fuel Cell Store) were used for the catalyst layer fabrication.

\section{Electrochemical measurements}

All electrochemical measurements were performed in a three-electrode system controlled by a potentiostat (ECi 200, Nordic Electrochemistry). If not specifically noted, the same electrochemical procedures (catalyst loadings, treatment, electrolyte, measurement protocol, 
etc.) were applied for the $\mathrm{Pd} / \mathrm{C}$ and $\mathrm{Pt} / \mathrm{C}$ catalyst. All measurements have been conducted at room temperature.

\section{Measurements in conventional electrochemical cell}

A glassy carbon electrode ( $5 \mathrm{~mm}$ diameter) was used as the working electrode, a platinum wire was used as counter electrode and a reversible hydrogen electrode (RHE) as reference electrode. The electrolyte was either $1.0 \mathrm{M} \mathrm{HClO}_{4}$ or $1.0 \mathrm{M} \mathrm{KOH}$ aqueous solution. The effective solution resistance was compensated to a value below $5 \Omega$ via an analogue positive feedback scheme of the potentiostat.

The catalyst ink for the RDE measurements was prepared by ultrasonically dispersing the catalyst powder $(0.276 \mathrm{mg}$ metal $)$ in $1.266 \mathrm{~mL}$ of a mixed solution containing isopropanol and water (1:3; v:v) and $11.04 \mu \mathrm{L}$ of $10 \mathrm{wt} \%$ Nafion solution to form a homogeneous catalyst ink with a metal concentration of $0.218 \mathrm{mg}_{\text {metal }} \mathrm{mL}^{-1}$. The RDE working electrodes were fabricated by pipetting $9 \mu \mathrm{L}$ of the electrocatalyst ink onto a glassy carbon electrode leading a nominal metal loading of $10 \mu \mathrm{g}_{\text {metal }} \mathrm{cm}^{-2}$ geo, followed by drying in air.

The electrolyte was deaerated by purging with Ar. Prior to the measurements the catalysts were cleaned by potential cycling between $0.15 \mathrm{~V}_{\mathrm{RHE}}$ and $1.20 \mathrm{~V}_{\mathrm{RHE}}$ at a scan rate of $500 \mathrm{mV} \mathrm{s} \mathrm{s}^{-1}$ until a stable cyclic voltammogram (CV) could be observed. The ECSA was determined via the $\mathrm{CO}$ oxidation charge in $\mathrm{CO}$ monolayer stripping experiments [24]. For this, the electrode was held at $0.15 \mathrm{~V}_{\mathrm{RHE}}$ in a CO-saturated electrolyte for 2 minutes. Thereafter the electrolyte was saturated for 10 min with Ar gas to replace the excess $\mathrm{CO}$ in the electrolyte. Finally, the adsorbed $\mathrm{CO}$ monolayer was oxidized to $\mathrm{CO}_{2}$ by scanning the electrode potential from 0.15 to $1.20 \mathrm{~V}_{\mathrm{RHE}}(\mathrm{Pd})$ or $1.10 \mathrm{~V}_{\mathrm{RHE}}(\mathrm{Pt})$ at a scan rate of $50 \mathrm{mV} \mathrm{s}^{-1}$. The ECSA was estimated from the recorded oxidation charge by using a reference oxidation charge value for polycrystalline Pt of $420 \mu \mathrm{C} \mathrm{cm}^{-2} \mathrm{Pt}$ [25] and $\mathrm{Pd}$ of $405 \mu \mathrm{C} \mathrm{cm}^{-2} \mathrm{Pd}$ [26], respectively. The cyclic voltammetry 
measurements were recorded in the same potential window and at the same scan rate of $50 \mathrm{mV}$ $\mathrm{s}^{-1}$, but in Ar-saturated electrolyte solution. The electrochemical oxidation of formic acid and methanol, respectively, was performed by collecting cyclic voltammetry curves in a Arsaturated electrolyte solution containing $1.0 \mathrm{M} \mathrm{HClO}_{4}$ and $0.5 \mathrm{M} \mathrm{HCOOH} ; 1.0 \mathrm{M} \mathrm{HClO}_{4}$ and $0.5 \mathrm{M} \mathrm{CH}_{3} \mathrm{OH}$; or $1.0 \mathrm{M} \mathrm{KOH}$ and $0.5 \mathrm{M} \mathrm{CH}_{3} \mathrm{OH}$ at a scan rate of $50 \mathrm{mV} \mathrm{s}^{-1}$ in a potential window between 0.15 and $1.20 \mathrm{~V}_{\mathrm{RHE}}$ (formic acid oxidation) or between 0.2 and $1.10 \mathrm{~V}_{\mathrm{RHE}}$ (methanol oxidation).

\section{Electrochemical measurements in gas diffusion electrode setup}

In the gas diffusion electrode setup, instead of the GC electrode, a GDE (3 mm diameter) was used as the working electrode (WE), a platinum wire as counter electrode (CE) and a reversible hydrogen electrode (RHE) as reference electrode (RE). The WE is separated from the CE and RE by a Nafion membrane [27] or an anion exchange membrane (for $\mathrm{KOH}$ solution) in the upper cell compartment above the membrane $1.0 \mathrm{M} \mathrm{HClO}_{4}$ or $1.0 \mathrm{M} \mathrm{KOH}$ aqueous solution was used as electrolyte. All gases purged through the GDE were humidified by first passing through MilliQ water [27] or the reactant solution.

WE preparation: The catalyst (0.382 $\mathrm{mg}$ metal) was ultrasonically dispersed in $7.645 \mathrm{~mL}$ of a mixed solution containing isopropanol, water (3:1; v:v) and $15.29 \mu \mathrm{L}$ of $10 \mathrm{wt} \%$ Nafion (10:1; $\mathrm{ul}: \mathrm{mg}_{\text {Carbon }}$ ) solution to form a homogeneous $0.05 \mathrm{mg}_{\text {metal }} \mathrm{mL}^{-1}$ catalyst ink. The catalyst was deposited on the GDL with a MPL by vacuum filtration (nominal loading $200 \mu \mathrm{g}_{\text {metal }} \mathrm{cm}^{-2}{ }_{\text {geo }}$ ) [28]. A blank GDL with MPL with a diameter of $2 \mathrm{~cm}$ was taken and a $3 \mathrm{~mm}$ hole was punched out in its centre. This was placed onto a GDL without MPL and in the hole a $3 \mathrm{~mm}$ catalyst coated GDL was placed and everything was pressed to a Nafion membrane of $1 \mathrm{~cm}$ in diameter by a hydraulic press ( 2 tons pressure). 
The system was deaerated by purging the GDE through the bottom cell part with humidified Ar [27]. Prior to the measurements the catalysts were cleaned by potential cycling between $0.15 \mathrm{~V}_{\mathrm{RHE}}$ and $1.20 \mathrm{~V}_{\mathrm{RHE}}$ at a scan rate of $500 \mathrm{mV} \mathrm{s}^{-1}$ until a stable $\mathrm{CV}$ could be observed, The CO stripping measurements were performed as in the conventional cell, i.e., the electrode was held at $0.15 \mathrm{~V}_{\mathrm{RHE}}$ with streaming $\mathrm{CO}$ through the cell for 2 minutes; thereafter the $\mathrm{CO}$ was replaced by $\mathrm{Ar}$ gas to remove all excess $\mathrm{CO}$. The adsorbed $\mathrm{CO}$ monolayer was oxidized to $\mathrm{CO}_{2}$ by scanning the electrode potential from 0.15 to $1.20 \mathrm{~V}_{\mathrm{RHE}}(\mathrm{Pd})$ or $1.10 \mathrm{~V}_{\mathrm{RHE}}(\mathrm{Pt})$ at a scan rate of $50 \mathrm{mV} \mathrm{s}^{-1}$. The ECSA was estimated from the recorded oxidation charge using the same reference values as in the RDE measurements.

The electrochemical oxidation of formic acid and methanol, respectively, was performed by passing Ar through 5.0 M HCOOH or $5.0 \mathrm{M} \mathrm{CH}_{3} \mathrm{OH}$ aqueous solution instead of pure MilliQ water. The cyclic voltammetry curves were collected at a scan rate of $50 \mathrm{mV} \mathrm{s}^{-1}$ in the same potential range as noted above.

\section{Physical characterization of the catalysts}

The size (diameter) and shape of the Pt and Pd nanocatalysts were evaluated by TEM using a Jeol 2100 transmission electron microscope operated at $200 \mathrm{kV}$. For the characterization, at least three images in at least three different randomly selected areas of the grids were chosen. The samples were prepared by dropping the catalyst inks ( the catalyst was diluted in ethanol) onto carbon coated copper TEM grids. The nanoparticle size was evaluated by measuring the diameter of at least 200 nanoparticles using the software ImageJ.

In order to evaluate the nanoparticle size with more statistical power (given that TEM analysis is limited to few hundreds of individual nanoparticles), small angle X-ray scattering were performed as previously described in detail [16]. The $\mathrm{Pd} / \mathrm{C}$ or $\mathrm{Pd} / \mathrm{C}$ powders were placed in dedicated holders in between two mica windows. The measurements performed at the Niels 
Bohr Institute at the University of Copenhagen using a SAXSLab instrument. The data were fitted with polydisperse spheres models described by a volume-weighted log-normal distribution.

\section{Inductively Coupled Plasma Mass Spectrometry (ICP-MS)}

The actual metal loadings of WE were evaluated by ICP-MS (NexION 2000 ICP-MS). The ICP-MS was equipped with a cyclonic spray chamber and a PFA-nebulizer. The RF power for the plasma was held at $1300 \mathrm{~W}$ with a gas flow of $15 \mathrm{~L} \mathrm{~min}^{-1}$. The catalysts on the GDLs were selected 4 different parts and dissolved in aqua regia (volume ratio of $\mathrm{HCl}: \mathrm{HNO}_{3}=3: 1$ ) and then diluted to $200 \mathrm{~mL}$ with milli-Q water. Based on four different measurements average metal loadings of $141 \mu \mathrm{g}_{\mathrm{Pd}} \mathrm{cm}^{-2}$ geo and $143 \mu \mathrm{g}_{\mathrm{Pt}} \mathrm{cm}^{-2}$ geo for $\mathrm{Pd} / \mathrm{C}$ and $\mathrm{Pt} / \mathrm{C}$, respectively, were determined. To evaluate the real catalyst loading on the RDE tips, $9 \mu$ of the catalyst ink was taken and dissolved in $4 \mathrm{~mL}$ aqua regia (volume ratio of $\mathrm{HCl}: \mathrm{HNO} 3=3: 1$ ) and then diluted to $25 \mathrm{~mL}$ with milli-Q water. By ICP-MS, metal loadings of $8.0 \mu \mathrm{g}_{\mathrm{Pd}} \mathrm{cm}^{-2}$ geo and $7.5 \mu \mathrm{g}_{\mathrm{Pt}} \mathrm{cm}^{-2}$ geo on the RDE tips were estimated.

\section{Results and Discussion}

As discussed in the introduction, the aim of this work is to establish the suitability of the GDE approach for volatile organic reactants and to compare the performance of two standard catalysts for the methanol and formic acid oxidation, i.e., $\mathrm{Pt} / \mathrm{C}$ and $\mathrm{Pd} / \mathrm{C}$ in two different setups: a conventional electrochemical cell (RDE setup) with aqueous supporting electrolyte to which the reactant, i.e., methanol or formic acid is added, and a GDE setup with a catalyst - membrane electrolyte interface where the reactant is introduced via a humidified gas stream. The experimental setup for the GDE measurements is new and to the best of our knowledge has not been previously used for studying the electro-oxidation of volatile small organic molecules. It is schematically displayed in Figure 1. Most importantly, in this configuration the catalyst has 
only contact to the reactant in water and the membrane electrolyte, but no solvated anions such as e.g., perchlorate anions.

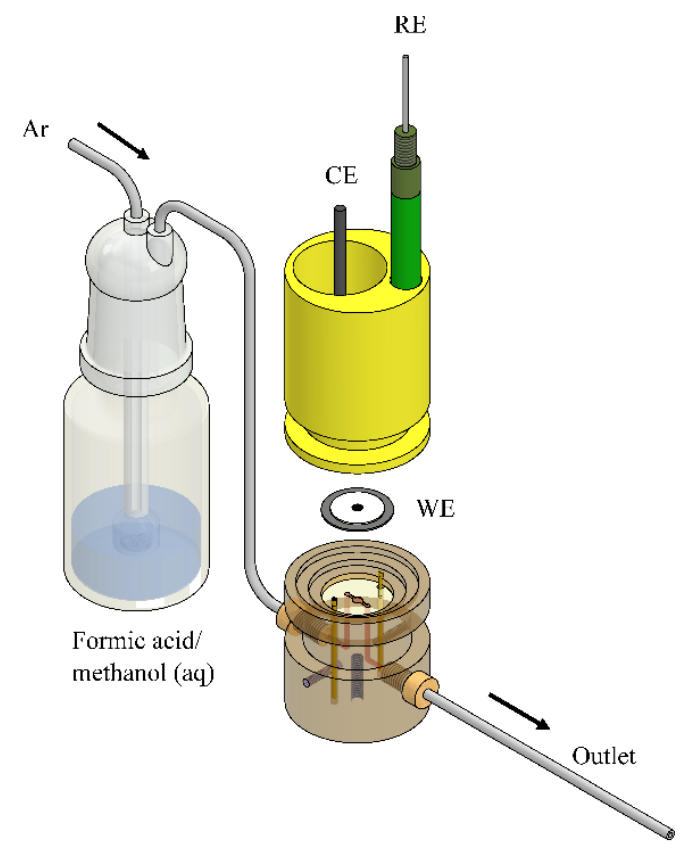

Figure 1. Sketch of the experimental setup for the GDE measurements. The formic acid or methanol is brought to the catalyst layer (WE) on the GDL via a humidified Ar gas stream. CE and RE indicate counter and reference electrode and are separated from the WE by a membrane electrolyte, i.e. proton or anion exchange membrane (not shown).

Before we discuss the results of the electrochemical measurements, we introduce the physical characterization by TEM and SAXS of the investigated commercial catalysts. TEM micrographs as well as the particle size distributions determined by TEM and SAXS are shown in Figure 2; the fits of the SAXS data are shown in Figure S1 in the supporting information. Both, the commercial $\mathrm{Pt} / \mathrm{C}$ and the $\mathrm{Pd} / \mathrm{C}$ exhibit homogeneously distributed nanoparticles on the carbon support and a well-defined particle size. Consistent results are obtained comparing the results of the local method TEM with the results of the "integrating" (i.e., probing a macroscopic part of the catalyst) method SAXS. The histogram of the particle size evaluated by TEM and the probability function determined by SAXS reveal an average size of $1.6 \pm 0.4$ $\mathrm{nm}$ and $1.8 \pm 0.2 \mathrm{~nm}$, respectively, for the $\mathrm{Pt} / \mathrm{C}$ catalyst. By comparison, the $\mathrm{Pd}$ particle size is 
slightly larger with an average size of $4.2 \pm 0.9 \mathrm{~nm}$ and $4.8 \pm 0.3 \mathrm{~nm}$, determined by TEM and SAXS, respectively.
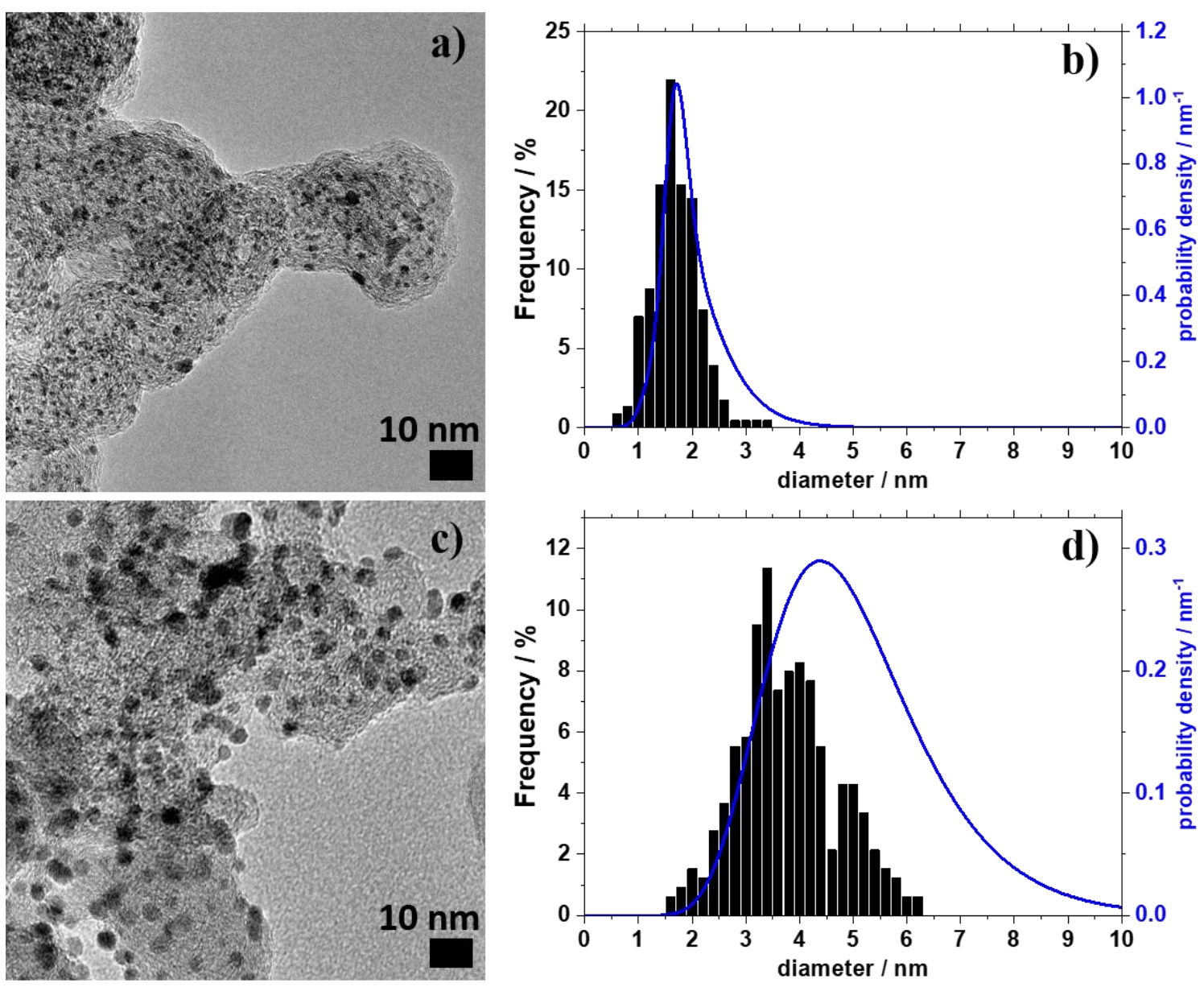

Figure 2. Representative TEM micrographs of the commercial Pt/C a) and Pd/C catalyst c); Particle size distributions derived from TEM (black size histogram) and SAXS (blue probability density function) of $\mathrm{Pt} / \mathrm{C} b)$ and $\mathrm{Pd} / \mathrm{C} d)$. For the particle size histograms 228 nanoparticles for Pt and 330 nanoparticles for $P d$ were analyzed.

Investigating the catalytic performance of fuel cell catalysts, one typically starts with recording CVs in inert atmosphere followed by a determination of the electrochemically active surface area (ECSA). The respective measurements for $\mathrm{Pt} / \mathrm{C}$ and $\mathrm{Pd} / \mathrm{C}$ are summarized in Figure 3. In the discussion we concentrate on the similarities and differences of the electrochemical behavior of the respective catalysts in the RDE and GDE setup. Independent of the electrochemical setup and the catalyst, all CVs confirm a "standard response" to the cycling of the electrode potential in inert atmosphere and a "clean" catalyst surface. Despite the different 
catalyst loadings and the resulting different current densities in the RDE and GDE setup, for both, $\mathrm{Pt} / \mathrm{C}$ and $\mathrm{Pd} / \mathrm{C}$ the electrochemical response in the two cell types is comparable. The typical responses of hydrogen under potential deposition $\left(\mathrm{H}_{\mathrm{upd}}\right)$ at low electrode potentials $\left(0.15-0.30 \mathrm{~V}_{\mathrm{RHE}}\right)$ and electrochemical oxide formation at higher potentials $\left(0.70-0.90 \mathrm{~V}_{\mathrm{RHE}}\right)$ are clearly discernible and well separated by a potential region double layer formation (ca. 0.30 $\left.-0.60 \mathrm{~V}_{\mathrm{RHE}}\right)$ on Pt and Pd [29,30].
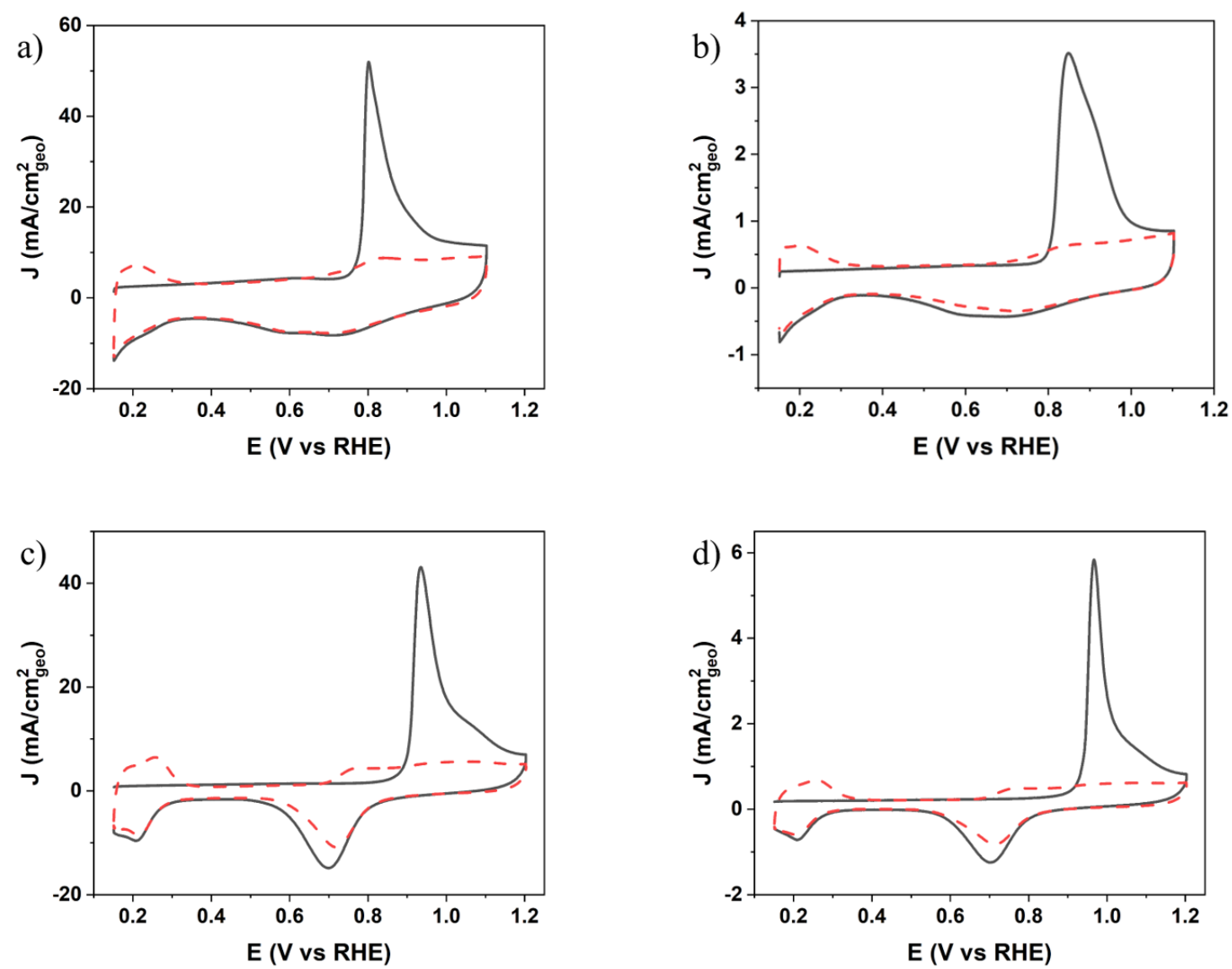

Figure 3. CVs (red dashed lines) and CO stripping voltammograms (black lines) recorded in GDE setup $(P t / C ; a), P d / C ; c))$ and in RDE setup $(P t / C ; b), P d / C ; d))$. The $C V s$ and $C O$ stripping voltammograms were recorded with a scan rate of $50 \mathrm{mV} \mathrm{s}^{-1}$ in Ar saturated $1.0 \mathrm{M} \mathrm{HClO}_{4}$ electrolyte (RDE) and under humidified Ar atmosphere (GDE), respectively. All measurements were recorded at room temperature.

Also the $\mathrm{CO}$ stripping voltammograms for $\mathrm{Pt} / \mathrm{C}$ and $\mathrm{Pd} / \mathrm{C}$ in both cell types are similar, but the peak potential and peak width are slightly different. For both catalysts, in the GDE setup the peak potential of the CO stripping peaks are slightly shifted to lower potentials as compared to 
the RDE measurements. These differences can in part due to the different thicknesses of the catalyst layers. In addition, the different electrolyte, i.e., aqueous electrolyte with mobile perchlorate anions and a membrane electrolyte, respectively, might influence the CO stripping voltammograms. That is, the interaction with perchlorate anions shifts slightly shifts the CO oxidation to higher potentials. The ECSA determination based on the CO stripping measurements is required when distinguishing between mass and surface area normalized (specific) currents. Furthermore, it can be used to confirm a full utilization of the catalyst layer in the GDE setup.

In RDE measurements typically a full utilization of the catalyst layer is achieved due to the very thin catalyst film (nominal catalyst loading of $10 \mu \mathrm{g}_{\text {metal }} \mathrm{cm}^{-2}$ geo on the GC electrode). However, in the GDE a roughly twenty times thicker catalyst layer is applied, similar to what is actually used in devices. As the GDE contains no liquid electrolyte in direct contact to the catalyst layer, a proper contact of the nanoparticles with the membrane electrolyte in the catalyst layer is required. Integrating the $\mathrm{CO}$ stripping voltammograms recorded in the conventional RDE setup leads to ECSA values of $\sim 153 \mathrm{~m}^{2} \mathrm{~g}^{-1} \mathrm{Pt}$ and $\sim 130 \mathrm{~m}^{2} \mathrm{~g}^{-1} \mathrm{Pd}$. A correction via the actual metal concentration in the inks by ICP-MS leads to even slightly higher values of $\sim 181 \mathrm{~m}^{2} \mathrm{~g}^{-1} \mathrm{Pt}$ and $149 \mathrm{~m}^{2} \mathrm{~g}^{-1} \mathrm{Pd}$ for Pt/C and Pd/C, respectively. The different ECSAs for Pt/C and $\mathrm{Pd} / \mathrm{C}$ can be roughly compared with the different average particle size of the two catalysts. Assuming the nanoparticles are perfect spheres and no interface between the metal surface and the carbon support, ECSAs of the "free standing particles" of $165 \mathrm{~m}^{2} \mathrm{~g}^{-1} \mathrm{Pt}$ and $119 \mathrm{~m}^{2} \mathrm{~g}^{-1} \mathrm{Pd}$ for $\mathrm{Pt} / \mathrm{C}$ and $\mathrm{Pd} / \mathrm{C}$, respectively, are calculated using the average particle size determined from TEM. Typically the surface area of "the free standing particles" is higher than the ECSA measured for "the supported particles" and the difference is assigned to the metal - support interface inaccessible for $\mathrm{CO}$ adsorption. In the present work, the correction of the ECSA values by the metal concentration measured in ICP-MS leads to higher ECSA values of "the 
supported particles". While the comparison is only a rough calculation, this finding might indicate that both catalysts contain many particles which are smaller than the average size determined by TEM.

By comparison the ECSA determination in the GDE setup (corrected by the catalyst loading determined by ICP-MS) led to values of $124 \mathrm{~m}^{2} \mathrm{~g}^{-1} \mathrm{Pt}$ and $123 \mathrm{~m}^{2} \mathrm{~g}^{-1} \mathrm{Pd}$ for $\mathrm{Pt} / \mathrm{C}$ and $\mathrm{Pd} / \mathrm{C}$, respectively. That is, the ECSA measured in the GDE setup tends to be slightly lower than in the RDE setup. This phenomenon might be related to the explained by the presence of Nafion in the GDE layer. Nafion is known to partially block the active surface area of the active catalyst phase and thus reduces the ECSA [21]. Although, we used also Nafion in the conventional cell with liquid electrolyte, the situation is different as the Nafion serves more as a binder to the glassy carbon tip. Due to the liquid electrolyte, no Nafion is required to "electrically contact" the active phase of the catalyst. As a consequence, in the following we normalize the reaction rates to the number of electrochemically active sites determined by $\mathrm{CO}$ stripping, i.e., we analyse and compare the specific activities in both setups.

After having characterized the catalysts in the supporting electrolyte (aqueous and membrane electrolyte) and having determined the number of electrochemically active sites, we first studied the methanol and formic acid electro-oxidation reactions. Before evaluating their catalytic properties, the electrocatalysts were first activated in Ar atmosphere by cyclic voltammetry until a stable curve shape was obtained and a CO-stripping measurement was performed. It has been noticed, that in the GDE setup and for Pd catalysts, different results were obtained, depending on whether a CO stripping voltammogram has been recorded before the electro-oxidation or not. Only after a CO stripping voltammogram was recorded, as in the cases discussed below, the catalyst was fully activated. In Figure S2 in the supporting information a comparison for the formic acid oxidation between a fully activated and an as 
prepared $\mathrm{Pd} / \mathrm{C}$ sample is shown. This phenomenon has not been investigated further, but might be related to hydride formation on $\mathrm{Pd}$ [31].
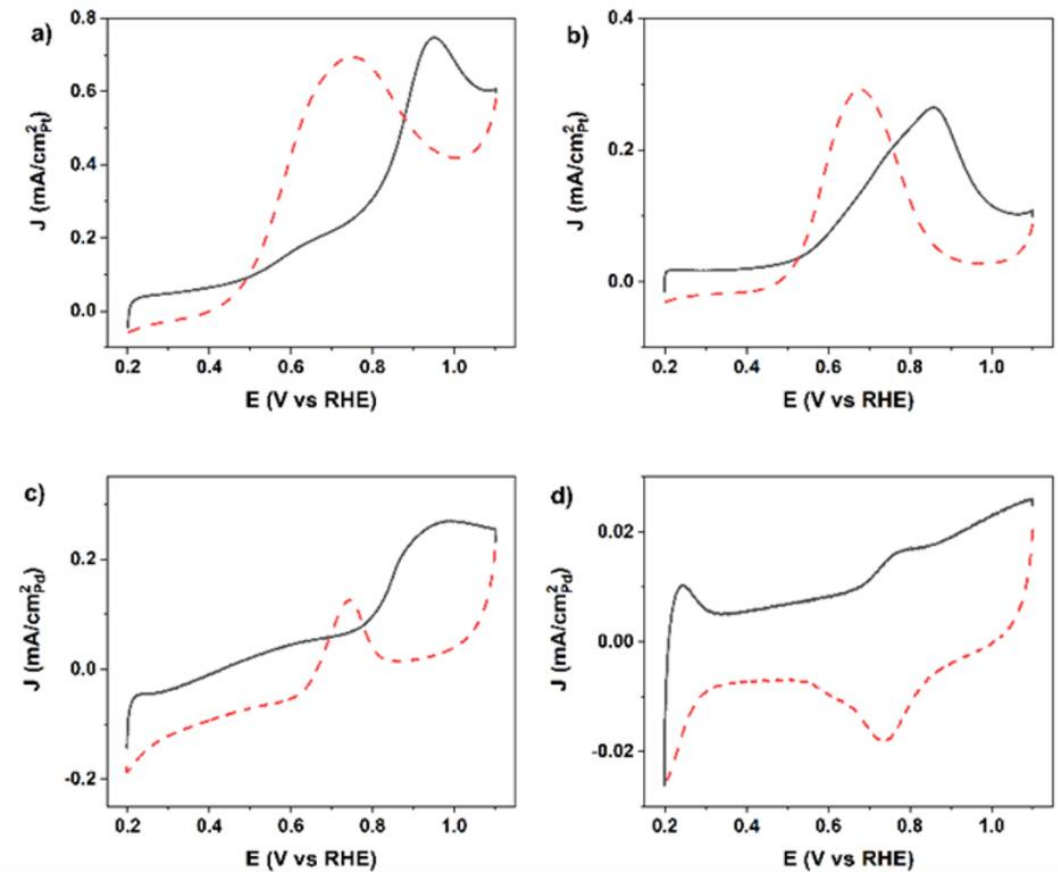

Figure 4. CVs recorded for Pt/C in the presence of methanol in a GDE setup (a) and in a RDE setup (b); CVs recorded for Pd/C in the presence of methanol in a GDE setup (c) and in a RDE setup (d). The black lines are the forward going scans, whereas the red dashed lines are the backward going scans. In the GDE setup the methanol was supplied by bubbling Ar gas through a $5.0 \mathrm{M}$ methanol aqueous solution; In the RDE setup the electrolyte was $1.0 \mathrm{M} \mathrm{HClO}_{4}$ aqueous solution containing $0.5 \mathrm{M}$ methanol. The CVs were recorded at a scan rate of $50 \mathrm{mV} \mathrm{s}^{-1}$ at room temperature and display the 2nd scan.

In Figure 4, the results from the electro-oxidation of methanol on commercial $\mathrm{Pt} / \mathrm{C}$ and $\mathrm{Pd} / \mathrm{C}$ recorded in GDE and RDE are summarized. For Pt/C similar trends are observed on the thicker catalyst films in the GDE and the very thin catalyst films in the RDE. Most prominent, in both systems a clear hysteresis is seen between the peak potential in the positive and negative going scan is observed. The hysteresis of the peak potential of the main oxidation peak, the maximum current density as well as the peak position (potential) where this is achieved are the main characteristics for an evaluation of the electro-oxidation of methanol. A hysteresis in the oxidation of small organic molecules typically indicates the formation of a $\mathrm{CO}$ poisoning species at the surface [32]. Therefore, it can be assumed that both setups surface poisoning 
occurs during the oxidation reaction. However, in the positive going scan in the GDE setup a pre-peak is seen, which starts around $0.5 \mathrm{~V}_{\mathrm{RHE}}$. Also the deactivation due to Pt oxide formation is less pronounced than in the RDE. Last but not least, the current densities normalized to the Pt surface area are roughly two times higher than in the RDE. This observation cannot be assigned to the difference in ECSA values obtained from the CO stripping, but might be related to the different methanol concentrations at the catalyst surface. However, at the chosen conditions no mass transport limitations are expected in the RDE setup. Therefore, it seems that in the GDE setup the same catalyst can provide higher specific activities than in an aqueous electrolyte. This might be further evidence of a lack of activity inhibition (as in the $\mathrm{CO}$ stripping voltammetry) due to (the lack of) specific anion adsorption in the GDE setup.

Switching to $\mathrm{Pd} / \mathrm{C}$ instead of $\mathrm{Pt} / \mathrm{C}$, in the $\mathrm{RDE} \mathrm{Pd} / \mathrm{C}$ is completely inactive for the methanol oxidation reaction and basically the same $\mathrm{CV}$ is recorded with and without the presence of methanol in the supporting electrolyte. The inactivity of Pd for the methanol oxidation is well established in aqueous acidic electrolyte and in contrast to alkaline electrolyte. Although in the GDE setup minor oxidation currents on $\mathrm{Pd} / \mathrm{C}$ are recorded, the reached current density high enough to be technologically relevant. In the GDE setup, the acidic Nafion membrane can be easily exchanged by an alkaline anion exchange membrane [14]. In Figure 5, it is demonstrated that in alkaline environment indeed $\mathrm{Pd} / \mathrm{C}$ is active for the methanol oxidation reaction. The features in both setups, i.e., GDE and RDE are similar. However, significantly larger specific current densities are recorded in the GDE setup. Roughly 25 times higher specific current densities are observed. In addition, in the negative going scan the re-activation of the Pd due to the reduction of the oxide is sharper and more pronounced. 

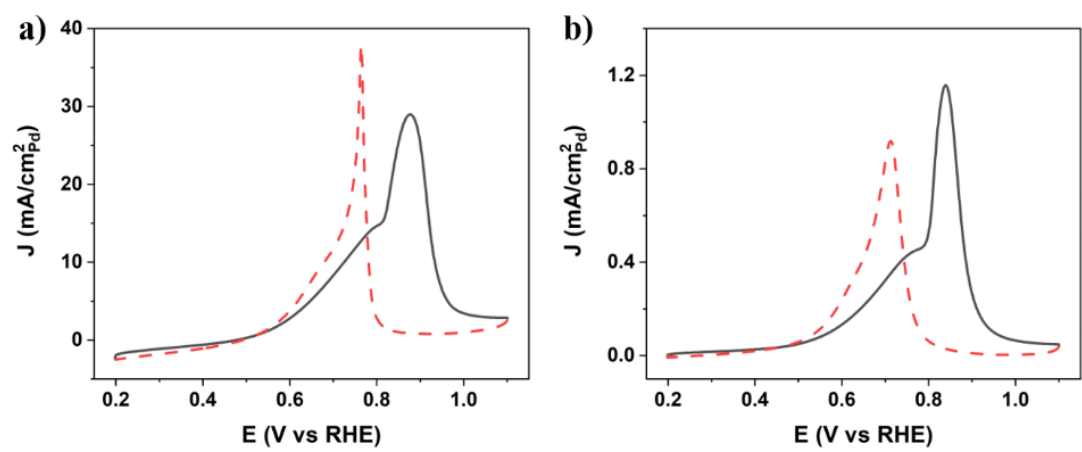

Figure 5. CVs recorded for Pd/C in the presence of methanol in a GDE setup containing an alkaline anion exchange membrane ( a) and in a RDE setup with $1.0 \mathrm{M}$ aqueous $\mathrm{KOH}$ containing $0.5 \mathrm{M}$ methanol (b). The black lines are the forward going scans, whereas the red dashed lines are the negative going scans. In the GDE setup the methanol was supplied by bubbling Ar gas through a $5.0 \mathrm{M}$ methanol aqueous solution; The CVs were recorded at a scan rate of $50 \mathrm{mV} \mathrm{s}^{-1}$ at room temperature and display the 2nd scan.

In addition to methanol, we also studied the electro-oxidation of formic acid on $\mathrm{Pt} / \mathrm{C}$ and $\mathrm{Pd} / \mathrm{C}$ in the two setups. The results are summarized in Figure 6. For the electro-oxidation of formic acid, the peak position (potential) of the main oxidation peak, its current density as well as the observed hysteresis between forward and backward going scan are also the main characteristics for an evaluation of the performance. The RDE measurements confirm the well-known fact that for formic acid oxidation in acidic environment, the performance of $\mathrm{Pt} / \mathrm{C}$ and $\mathrm{Pd} / \mathrm{C}$ "are reverse" to the electro-oxidation of methanol. That is, while formic acid oxidation on $\mathrm{Pt} / \mathrm{C}$ is strongly inhibited and a large hysteresis is seen, $\mathrm{Pd} / \mathrm{C}$ exhibits a low peak potential, high current densities, and little hysteresis. Comparing the RDE to the GDE results, it is apparent that in the GDE the formic acid oxidation on Pt/C is less inhibited based on the observed hysteresis, however, the observed current densities are rather low. More interesting are the results for $\mathrm{Pd} / \mathrm{C}$. It is seen that the performance based on peak position in the positive going scan direction is significantly improved in GDE setup. The peak potential of the main oxidation peak is shifted by roughly $100 \mathrm{mV}$ to lower potentials, which can be associated with an reduced overpotential. At the same time peak current density is roughly the same. Again, this difference between GDE and RDE might be correlated to specific anion adsorption. The onset of formic acid oxidation 
is associated with the desorption of $\mathrm{H}_{\text {upd. }}$ In an aqueous acid electrolyte there will be always an interplay between $\mathrm{H}_{\text {upd }}$ desorption and anion adsorption while in membrane electrolyte no mobile anions exist. However, in the GDE a clear hysteresis and asymmetric oxidation peaks are seen in the negative going scan. It seems that in the GDE, at higher electrode potentials (> $0.4 \mathrm{~V}_{\mathrm{RHE}}$ ), the $\mathrm{Pd} / \mathrm{C}$ catalyst becomes inhibited by the formation of surface poisoning species, while this seems not to be the case in the RDE measurements.
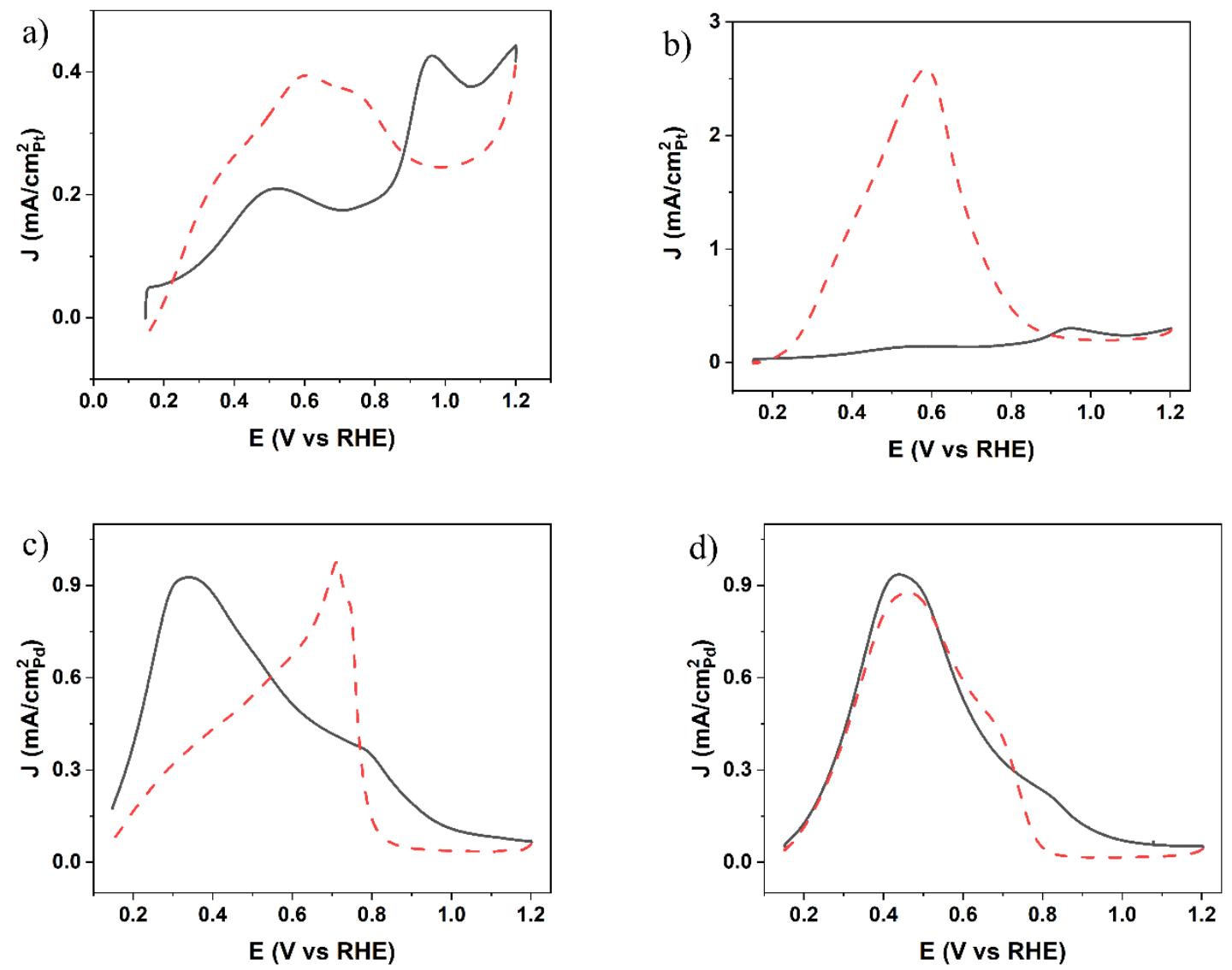

Figure 6. CVs of formic acid oxidation with Pt/C (a) and Pd/C (c) recorded in a GDE setup as well as $P t / C(b)$ and $P d / C(d)$ measured in a RDE setup; all curves were recorded at room temperature with a scan rate of $50 \mathrm{mV} \mathrm{s}^{-1}$ and display the $2 \mathrm{nd}$ scan. In the GDE, Ar was bubbled through $5.0 \mathrm{M}$ formic acid aqueous solution. The electrolyte in the RDE was $1.0 \mathrm{M} \mathrm{HClO}_{4}+0.5 \mathrm{M}$ formic acid.

\section{Conclusion}

In the presented work, the application of a GDE setup for the electro-oxidation of volatile small organic molecules is presented. Both methanol and formic acid are potential fuels for fuel cells, 
i.e., so-called direct methanol/formic acid fuel cells. It is shown that the GDE setup that has been previously used for the investigation of oxygen reduction reaction catalysts can be easily adopted for the study of these reactants. The reactant is simply introduced via the humidification of the gas stream. In contrast to the conventional RDE technique, catalyst films with realistic thicknesses for applications are studied in the GDE setup. Furthermore, the catalyst is not in direct contact to a liquid electrolyte, but a catalyst - membrane electrolyte interface is formed. Comparing the electrochemical responses in the two systems in a qualitative fashion, similar electrochemical behavior is observed in the RDE and GDE. Nevertheless, differences in specific activity and the peak potential of the main oxidation peak, and the hysteresis between positive and negative going scan be observed, which might be important for an extrapolation of the results from a catalyst screening to their use in direct methanol or direct formic acid fuel cells. The GDE approach therefore provides an important addition to the RDE approach in order to bridge the gap to MEA testing.

\section{Acknowledgements}

This work was supported by the Swiss National Science Foundation (SNSF) via the project No. 200021_184742. Damin Zhang and Jia Du acknowledge funding from the China Scholarship Council (CSC). Jonathan Quinson acknowledges the European Union's Horizon 2020 research and innovation program under the Marie Skłodowska-Curie grant agreement No. 840523 (CoSolCat). S. B. Simonsen and L. Theil Kuhn, Technical University of Denmark, are thanked for access to TEM. The Niels Bohr Institute, University of Copenhagen, for access to SAXS equipment and in particular J. J. K. Kirkensgaard. Gustav K.H. Wiberg, University of Bern, is acknowledged for the sketch in Figure 1.

\section{References}

[1] A. Kongkanand, M.F. Mathias, The Priority and Challenge of High-Power Performance 
of Low-Platinum Proton-Exchange Membrane Fuel Cells, J. Phys. Chem. Lett. 7 (2016) 1127-1137. https://doi.org/10.1021/acs.jpclett.6b00216.

[2] T. Yoshida, K. Kojima, Toyota MIRAI Fuel Cell Vehicle and Progress Toward a Future Hydrogen Society, Electrochem. Soc. Interface. 24 (2015) 45-49. https://doi.org/10.1149/2.F03152if.

[3] L. Carrette, K.A. Friedrich, U. Stimming, Fuel Cells - Fundamentals and Applications, Fuel Cells. 1 (2001) 5-39. https://doi.org/10.1002/1615-6854(200105)1:1<5::aidfuce $5>3.0 . c 0 ; 2-\mathrm{g}$.

[4] X. Yu, P.G. Pickup, Recent advances in direct formic acid fuel cells (DFAFC), J. Power Sources. 182 (2008) 124-132. https://doi.org/10.1016/j.jpowsour.2008.03.075.

[5] M. Inaba, J. Quinson, J.R. Bucher, M. Arenz, On the preparation and testing of fuel cell catalysts using the thin film rotating disk electrode method, J. Vis. Exp. 2018 (2018). https://doi.org/10.3791/57105.

[6] B. Han, C.E. Carlton, A. Kongkanand, R.S. Kukreja, B.R. Theobald, L. Gan, R. O’Malley, P. Strasser, F.T. Wagner, Y. Shao-Horn, Record activity and stability of dealloyed bimetallic catalysts for proton exchange membrane fuel cells, Energy Environ. Sci. 8 (2015) 258-266. https://doi.org/10.1039/c4ee02144d.

[7] A.R. Kucernak, E. Toyoda, Studying the oxygen reduction and hydrogen oxidation reactions under realistic fuel cell conditions, Electrochem. Commun. (2008). https://doi.org/10.1016/j.elecom.2008.09.001.

[8] C.M. Zalitis, D. Kramer, A.R. Kucernak, Electrocatalytic performance of fuel cell reactions at low catalyst loading and high mass transport, Phys. Chem. Chem. Phys. (2013). https://doi.org/10.1039/c3cp44431g.

[9] G.K.H.G.K.H. Wiberg, M. Fleige, M. Arenz, Gas diffusion electrode setup for catalyst testing in concentrated phosphoric acid at elevated temperatures, Rev. Sci. Instrum. 86 (2015). https://doi.org/10.1063/1.4908169.

[10] B.A. Pinaud, A. Bonakdarpour, L. Daniel, J. Sharman, D.P. Wilkinson, Key Considerations for High Current Fuel Cell Catalyst Testing in an Electrochemical Half- 
Cell, J. Electrochem. Soc. (2017). https://doi.org/10.1149/2.0891704jes.

[11] K. Ehelebe, J. Knöppel, M. Bierling, B. Mayerhöfer, T. Böhm, N. Kulyk, S. Thiele, K. Mayrhofer, S. Cherevko, Platinum Dissolution in Realistic Fuel Cell Catalyst Layers, Angew. Chemie Int. Ed. (2021). https://doi.org/10.1002/anie.202014711.

[12] K. Ehelebe, D. Seeberger, M.T.Y. Paul, S. Thiele, K.J.J. Mayrhofer, S. Cherevko, Evaluating Electrocatalysts at Relevant Currents in a Half-Cell: The Impact of Pt Loading on Oxygen Reduction Reaction, J. Electrochem. Soc. 166 (2019) F1259F1268. https://doi.org/10.1149/2.0911915jes.

[13] M. Inaba, A.W. Jensen, G.W. Sievers, M. Escudero-Escribano, A. Zana, M. Arenz, Benchmarking high surface area electrocatalysts in a gas diffusion electrode: measurement of oxygen reduction activities under realistic conditions, Energy Environ. Sci. 11 (2018) 988-994. https://doi.org/10.1039/C8EE00019K.

[14] S. Alinejad, J. Quinson, J.J. Schröder, J.J.K. Kirkensgaard, M. Arenz, J. J. K. Kirkensgaard, M. Arenz, J.J.K. Kirkensgaard, M. Arenz, Carbon-Supported Platinum Electrocatalysts Probed in a Gas Diffusion Setup with Alkaline Environment: How Particle Size and Mesoscopic Environment Influence the Degradation Mechanism, ACS Catal. 10 (2020) 13040-13049. https://doi.org/10.1021/acscatal.0c03184.

[15] S. Alinejad, M. Inaba, J. Schröder, J. Du, J. Quinson, A. Zana, M. Arenz, Testing fuel cell catalysts under more realistic reaction conditions: accelerated stress tests in a gas diffusion electrode setup, J. Phys. Energy. 2 (2020) 024003. https://doi.org/10.1088/2515-7655/ab67e2.

[16] J. Schröder, J. Quinson, J.K. Mathiesen, J.J.K. Kirkensgaard, S. Alinejad, V.A. Mints, K.M.Ø. Jensen, M. Arenz, A New Approach to Probe the Degradation of Fuel Cell Catalysts under Realistic Conditions: Combining Tests in a Gas Diffusion Electrode Setup with Small Angle X-ray Scattering, J. Electrochem. Soc. (2020). https://doi.org/10.1149/1945-7111/abbdd2.

[17] L. Pan, S. Ott, F. Dionigi, P. Strasser, Current challenges related to the deployment of shape-controlled Pt alloy oxygen reduction reaction nanocatalysts into low Pt-loaded cathode layers of proton exchange membrane fuel cells, Curr. Opin. Electrochem. 18 
(2019) 61-71. https://doi.org/10.1016/j.coelec.2019.10.011.

[18] J. Schröder, V.A. Mints, A. Bornet, E. Berner, M. Fathi Tovini, J. Quinson, G.K.H. Wiberg, F. Bizzotto, H.A. El-Sayed, M. Arenz, The Gas Diffusion Electrode Setup as Straightforward Testing Device for Proton Exchange Membrane Water Electrolyzer Catalysts, JACS Au. 1 (2021) 247-251. https://doi.org/10.1021/jacsau.1c00015.

[19] F.R. Nikkuni, B. Vion-Dury, L. Dubau, F. Maillard, E.A. Ticianelli, M. Chatenet, The role of water in the degradation of $\mathrm{Pt} 3 \mathrm{Co} / \mathrm{C}$ nanoparticles: An Identical Location Transmission Electron Microscopy study in polymer electrolyte environment, Appl. $\begin{array}{llll}\text { Catal. } & \text { B } & \text { Environ. 301-306. }\end{array}$ https://doi.org/10.1016/j.apcatb.2014.03.029.

[20] N.M. Markovíc, P.N. Ross, Surface science studies of model fuel cell electrocatalysts, Surf. Sci. Rep. 45 (2002) 117-229. https://doi.org/10.1016/s0167-5729(01)00022-x.

[21] K. Kodama, A. Shinohara, N. Hasegawa, K. Shinozaki, R. Jinnouchi, T. Suzuki, T. Hatanaka, Y. Morimoto, Catalyst Poisoning Property of Sulfonimide Acid Ionomer on $\begin{array}{lllllll}\text { Pt (111) Surface, J. Electrochem. } & \text { Soc. } 161 & \text { (2014) F649-F652. }\end{array}$ https://doi.org/10.1149/2.051405jes.

[22] K. Shinozaki, Y. Morimoto, B.S. Pivovar, S.S. Kocha, Re-examination of the Pt Particle Size Effect on the Oxygen Reduction Reaction for Ultrathin Uniform Pt/C Catalyst Layers without Influence from Nafion, Electrochim. Acta. 213 (2016) 783-790. https://doi.org/10.1016/j.electacta.2016.08.001.

[23] D. Strmcnik, K. Kodama, D. Van Der Vliet, J. Greeley, V.R. Stamenkovic, N.M. Marković, The role of non-covalent interactions in electrocatalytic fuel-cell reactions on platinum, Nat. Chem. 1 (2009) 466-472. https://doi.org/10.1038/nchem.330.

[24] M. Inaba, J. Quinson, J.R. Bucher, M. Arenz, On the Preparation and Testing of Fuel Cell Catalysts Using the Thin Film Rotating Disk Electrode Method, J. Vis. Exp. 133 (2018) e57105. https://doi.org/10.3791/57105.

[25] S. Rudi, C. Cui, L. Gan, P. Strasser, Comparative Study of the Electrocatalytically Active Surface Areas (ECSAs) of Pt Alloy Nanoparticles Evaluated by Hupd and COstripping voltammetry, $\quad$ Electrocatalysis. $\quad 5 \quad$ (2014) 408-418. 
https://doi.org/10.1007/s12678-014-0205-2.

[26] T. Chierchie, C. Mayer, W.J. Lorenz, Structural changes of surface oxide layers on palladium, J. Electroanal. Chem. Interfacial Electrochem. 135 (1982) 211-220. https://doi.org/10.1016/0368-1874(82)85121-6.

[27] M. Inaba, A.W. Jensen, G.W. Sievers, M. Escudero-Escribano, A. Zana, M. Arenz, Benchmarking high surface area electrocatalysts in a gas diffusion electrode: Measurement of oxygen reduction activities under realistic conditions, Energy Environ. Sci. 11 (2018). https://doi.org/10.1039/c8ee00019k.

[28] V. Yarlagadda, S.E. McKinney, C.L. Keary, L. Thompson, B. Zulevi, A. Kongkanand, Preparation of PEMFC Electrodes from Milligram-Amounts of Catalyst Powder, J. Electrochem. Soc. 164 (2017) F845-F849. https://doi.org/10.1149/2.1461707jes.

[29] T. Solomun, Electro-oxidation of the Pd (100) surface, J. Electroanal. Chem. Interfacial Electrochem. 255 (1988) 163-177. https://doi.org/10.1016/0022-0728(88)80012-3.

[30] M. Inaba, J. Quinson, M. Arenz, pH matters: The influence of the catalyst ink on the oxygen reduction activity determined in thin film rotating disk electrode measurements, J. Power Sources. 353 (2017) 19-27. https://doi.org/10.1016/j.jpowsour.2017.03.140.

[31] A. Kongkanand, N.P. Subramanian, Y. Yu, Z. Liu, H. Igarashi, D.A. Muller, Achieving High-Power PEM Fuel Cell Performance with an Ultralow-Pt-Content Core-Shell Catalyst, ACS Catal. 6 (2016) 1578-1583. https://doi.org/10.1021/acscatal.5b02819.

[32] M. Baldauf, D.M. Kolb, Formic acid oxidation on ultrathin Pd films on Au(hkl) and Pt(hkl) electrodes, J. Phys. Chem. $100 \quad$ (1996) 11375-11381. https://doi.org/10.1021/jp952859m. 


\section{Supporting information}

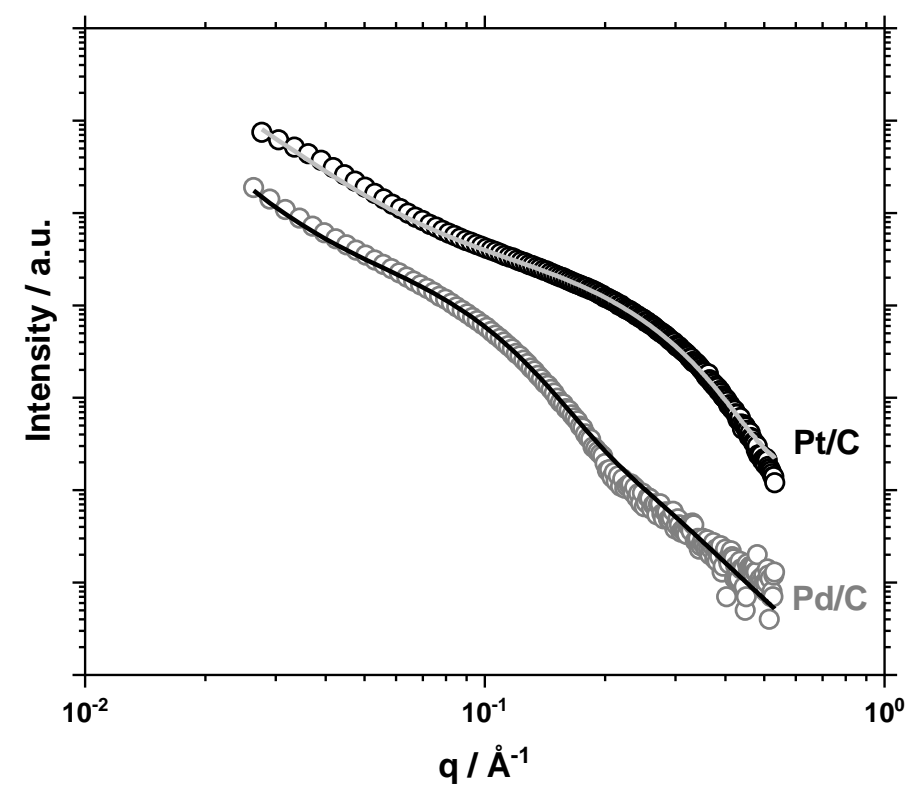

Figure S1. SAXS data (circles) and fits (lines) for the Pt/C and Pd/C samples, as indicated, after background subtraction. The two data set are presented with an offset for the sake of clarity.

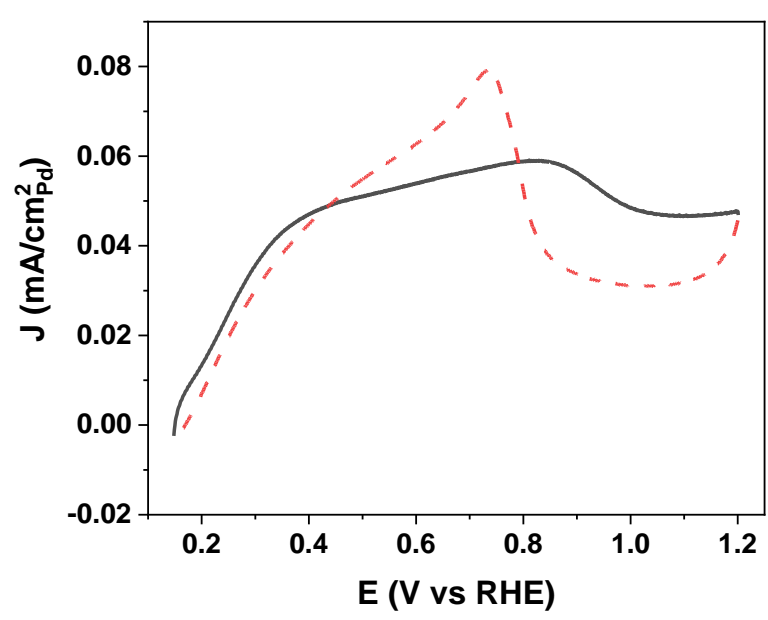

Figure S2. CVs of formic acid oxidation with a pristine $P d / C$ catalyst (no prior CO stripping voltammogram recorded) measured in a GDE setup at room temperature and a scan rate of $50 \mathrm{mV} \mathrm{s^{-1 }}$. 
Ar was bubbled 5.0 M formic acid aqueous solution. The upper cell compartment was filled with 1.0 $\mathrm{M} \mathrm{HClO}_{4}$. It is seen that the formic acid oxidation with a $\mathrm{Pd} / \mathrm{C}$ catalyst in its pristine state is significantly inhibited. See also Figure 6. 